\title{
Article \\ Setting Individual Goals for Pupils with Profound Intellectual and Multiple Disabilities-Engaging in the Activity Area-Based Curriculum Making
}

\author{
Satu Peltomäki ${ }^{1, *}$, Raija Pirttimaa ${ }^{2}$, Kirsi Pyhältö ${ }^{1,3}$ and Elina K. Kontu ${ }^{4}$ \\ 1 Faculty of Educational Sciences, University of Helsinki, 00014 Helsinki, Finland; kirsi.pyhalto@helsinki.fi \\ 2 Department of Education, University of Jyväskylä, 40014 Jyväskylä, Finland; raija.pirttimaa@jyu.fi \\ 3 Centre for Higher and Adult Education, Stellenbosch University, Stellenbosch 7602, South Africa \\ 4 Faculty of Social Sciences, Tampere University, 33014 Tampere, Finland; elina.kontu@tuni.fi \\ * Correspondence: satu.peltomaki@helsinki.fi
}

Citation: Peltomäki, S.; Pirttimaa, R.; Pyhältö, K.; Kontu, E.K. Setting Individual Goals for Pupils with Profound Intellectual and Multiple Disabilities-Engaging in the Activity Area-Based Curriculum Making. Educ. Sci. 2021, 11, 529. https:// doi.org/10.3390/educsci11090529

Academic Editor: Mona Holmqvist

Received: 22 July 2021

Accepted: 2 September 2021

Published: 10 September 2021

Publisher's Note: MDPI stays neutral with regard to jurisdictional claims in published maps and institutional affiliations.

\begin{abstract}
The activity area-based curriculum model (AACM) is used in the Finnish basic education to support pupils - most of whom have profound intellectual and multiple disabilities (PIMD) who could benefit more from skills that advance independent life coping. Existing studies have concentrated mainly on the Individual Education Plan (IEP) goal-setting process for pupils with milder disabilities than PIMD and have consistently demonstrated significant barriers in the process. This study explores the collaborative IEP goal-setting process for pupils with the AACM. Sixty-five Finnish special education teachers using the AACM participated in the study. Semi-structured interviews were analysed with thematic network analysis. The groups involved in the IEP goalsetting process were divided into main and side mediators. The main mediators were described as significant collaborators with important knowledge of the pupil, while side mediators rarely participated in the process. The special education teachers appeared to be leading the collaboration and were positioned in the middle of the main and side mediators. Further research should focus on the implementation of parents' collaborative positions. Furthermore, practices and methods should be developed to reinforce the positions of group home staff, special education teacher colleagues and pupils with the AACM or PIMD themselves.
\end{abstract}

Keywords: Individual Education Plan; activity-area based curriculum model; profound intellectual and multiple disabilities; goal-setting; collaboration; curriculum; semi-structured interviews; thematic network analysis

\section{Introduction}

This study investigates the collaboration in the Individual Education Plan (IEP) goalsetting process for pupils with the activity area curriculum model (AACM). Most of these pupils have profound intellectual and multiple disabilities (PIMD). Reproducing the results of Eckhoff and Weiss' [1] (p. 278) concept analysis, the IEP goal-setting process is seen as "the action of a 'Multiprofessional team setting goals for a pupil' ('Multiprofessional team setting goals for a pupil' substitutes the original term 'person' in the concept analysis [1]) who has the confidence, commitment, motivation, and knowledge necessary to attain a goal that is specific, challenging, measurable, and relevant within a specified amount of time".

The support system of the Finnish national core curriculum for basic education [2] is divided into three tiers depending on how intensive the support required by the pupil. The first tier, general support, is given as soon as the need for support appears. The need for the second tier, intensified support, is estimated through a pedagogical assessment. Intensified support is more long-lasting than general support, and it enables supporting the pupil more substantially. The third tier, special support, is used, when the goals for the pupil's growth, 
development and learning are not adequately achieved with intensified support. The need for special support is estimated in a pedagogical statement and planned in an IEP, which is based on the Basic Education Act [3]. The Finnish IEP is "a written plan containing the goals and contents of the pupil's learning and school attendance, the teaching arrangements to be used, pedagogical methods and the support and guidance needed by the pupil" [2] (p. 67), and has many similarities with IEPs used in other countries, e.g., Sweden and the USA [4,5]. The IEP is prepared annually and updated when necessary [6] (17a §).

The preparation of an IEP is a collaborative process with varying participants. These participants mediate different kinds and different amounts of information to each other and, in the text, are thus referred to as mediators. The IEP is devised by the pupil's teacher and, "unless there is a manifest excuse not to do so, in collaboration with the pupil, the parent or carer or, where needed, some other legal representative of the pupil" [6] (17a §). The teacher is in charge of the plan. Other professionals (e.g., therapists) can participate in the process if necessary [2] (p. 67). These mediators can work in schools or in other professional services. Finnish education providers are legally obligated to provide pupils with welfare services, which include services of a psychologist, school social worker and school health care [7]. In addition, depending on school and municipality, various therapists might work with the pupil, either provided by the school or by representing other professional services. Therapies are based on rehabilitation plans, which can be utilised in the IEP process or vice versa. However, the documents are separate, and the rehabilitation plan is neither implemented nor assessed at school. The more specific collaboration between these mediators is decided on locally [2] (pp. 75-76). Other countries, including Sweden, Turkey and Portugal $[4,8,9]$, have similar regulations concerning the collaboration with parents, pupils and other mediators in the IEP process. Despite regulations, Finnish education providers and teachers exercise a high level of autonomy; see [2] (pp. 75-76). Consequently, the implementation of the IEP process in detail varies between municipalities, schools and teachers.

Pupils receiving special support can study individualised syllabi in one or more subjects if necessary. The AACM is another model of special support, and it is used with pupils who are not expected to be able to study the individual syllabi of subjects but could benefit more from skills that advance independent life coping [2] (pp. 71-72). Instead of school subjects, the curriculum model has five activity areas: cognitive skills, social skills, language and communication, activities of daily living, and motor skills [2] (pp. 71-72), which are based on the primary stages of child development [10]. These pupils might have PIMD, other intellectual disabilities or severe disease [3] (18 §), [11] (9 § 3 mom). Most pupils with the AACM have PIMD, but no exact information on the group's heterogeneity exists. In 2019, approximately 2100 pupils were studying according to the AACM, which was 4.4 per cent of all pupils receiving special support in Finland [12]. Teaching and thus, the IEP, when implementing the AACM, are based on each pupil's strengths [2] (p. 71). Individual annual goals are central in their IEPs, and the goals are formulated according to the five activity areas mentioned above (pp. 67-72).

\section{Background to the Research}

\subsection{Challenges and Collaboration in the IEP Goal-Setting Process}

It has been suggested that goals are a key driver for high-quality learning in terms of both the process and the resulted outcomes when properly set; see, e.g., [13-15]. Eckhoff and Weiss [1] (p. 277) proposed four antecedents essential for a goal-setting process to succeed: commitment to the goal; motivation to set and attain the goal; self-efficacy or confidence in attaining the goal; and knowledge or skill level of the individual in a method to attain the goal; see also [15]. Furthermore, the goals should be specific, measurable, relevant, challenging, and have an endpoint [1]. These five elements have been highlighted as difficult to implement, concerning goal setting for pupils with and without intellectual disabilities in IEP goal setting research related to these pupils; e.g., [13,16-19]. In Finland, Räty and colleagues [20] found similar results when analysing the support measures 
described in the IEPs for pupils with intellectual disabilities. In addition, teachers have described the IEP process as laborious and time-consuming, and that they have been lacking sufficient assistance [21].

Participation in the IEP process is parents' and pupils' right [6] (17 a §). They also have unique information about the pupil's life and future hopes. Their participation enables the setting of meaningful goals for the pupil, which for its part, strengthens the pupil's engagement with the goal. Pupil engagement has been found to be a significant predictor of outcomes; Ruble and McGrew [15] showed it to be more significant than IQ, language, or autism severity; see also [1,22]. In addition, a pupil's participation reinforces their active agency in civil society, which is a central part of the basic values of the Finnish national core curriculum for basic education [2] (pp. 15-16).

Previous research on parents' and pupils' participation in the IEP process, some of which involves pupils with intellectual disabilities, has focused on their participation levels [23] and regional discrepancies [24]; parents' experiences [25,26], input [27], and interactions during the IEP meeting [28]; pupils' roles [29]; and student-led IEP meetings [30]. However, this previous research has revealed a power imbalance between schools and families, which can lead to families having a diminished role in the process. Families have often been left outside the decision-making process and decisions concerning goals might have been made before the meeting; see [17,27,28,31-33]. In addition, pupils' participation has been reported as being notably sparse, especially among pupils with lower functional cognitive and social skills; see [23,29,34-37].

Previous research regarding the IEP goal-setting process has focused on collaboration with parents $[25,28]$, pupils' and parents' participation [24], inclusive and integrative settings [38], teachers' professional learning [39], and IEP goal quality [13,16]. The studies have concentrated notably on pupils who study the basic school subjects either individually or according to mainstream education and have disabilities other than intellectual disabilities; see $[17,34,40]$. This previous research has demonstrated that the goal-setting process is a multidimensional complex with various implementation methods, pitfalls, contradictions and power, and shows a significant research gap in intellectual disability studies. Furthermore, studies concentrating on pupils with PIMD are even more sparse.

\subsection{Setting Goals for Pupils with Profound Intellectual and Multiple Disabilities}

PIMD is seen as profound intellectual disabilities, which are often integrated into motor disabilities and additional severe or profound disabilities or impairments [41]. Pupils with PIMD tend to need extensive and pervasive support at school and in their everyday lives; see [42] (p. 152). Legislation and the AACM with the rest of the national core curriculum for basic education [2] set the ground rules for these pupils' goals in Finland, but also leave abundant power with the IEP teams, as described in the introduction.

The IEP has been described as "the conceptual and practical intersection of policy, schools, and families of students with disabilities. As such, it most definitely is the foundation for effective special education and related services and positive student outcomes." [17] (p. 12). Collaboration with home, school personnel, therapists and other professionals promote the idea that the IEP goals can be practised in various settings systematically, and with several repetitions; see [32]. Repetition, and thus, collaboration, are especially important with pupils with PIMD because of the gradual development and the complexity of their needs. Furthermore, both time and life experience enhance the skills of these pupils, even though the development of a certain skill would appear to have stopped [43] (p. 79).

Research on participation by other IEP team members (e.g., other teachers, therapists, principals) and their roles appears to be underrepresented in research, especially in intellectual disability and PIMD research. Research has focused significantly more on pupils with other kinds of special needs $[35,37,44]$, where the teams also differ from ones built for pupils with the AACM or PIMD. However, the team-level structure, interaction, and communication are strongly connected to the IEP decision-making process and quality $[31,39,45,46]$, 
and each mediator provides the team with their special knowledge. Thus, research on the whole IEP team's goal-setting collaboration for pupils with PIMD is essential.

Stroggilos and Xanthacou [32] focused on studying team-level collaboration in the design and implementation of IEPs for pupils with PIMD. In their study, the professionals (teachers, speech and language therapists, physiotherapists and parents) did not work collaboratively; they did not discuss or share the goals, and rarely discussed other parts of the IEP [32]. In addition, Ruppar and Gaffney [31] studied in-depth interactions and the decision-making process among IEP team members. Their study pointed out that collaboration and decision-making in the IEP goal-setting process for a pupil with severe disabilities are a complex ensemble [31]. For example, many team members had diverging views from the decisions made at the meeting that they had not expressed [31]. This brings a need for research: how is it over a decade later and in different settings?

To conclude, the findings of those few studies that concentrated on the IEP goal-setting process for pupils with PIMD have shown that IEP teams' collaboration can be problematic, and various elements, such as the structure of IEP meetings and communication prior to the actual meeting, can influence the decisions; see $[31,32,47]$. Therefore, research is needed about the multi-professional teams' structure considering pupils with the AACM and how their individual goals are formed in the collaborative decision-making process. Pupils' teachers are in charge of the process and their views are therefore central. Knowledge of the collaborative decision-making process is critical for educational equality to be fulfilled. To optimise the goals that are set, we must understand their formulation process; see [48] (p. 947).

\section{Purpose of the Present Study}

The focus in this study is on exploring how goals in the IEPs are set for pupils with the AACM. Together with the rest of the national core curriculum, the model sets grounds for these pupils' IEP goals. However, the curriculum model also leaves a lot of responsibility with municipalities, schools and teachers. The aim of this study is to investigate the collaboration in the IEP goal-setting process for pupils with the AACM, and how that relates to the grounds of the goals. This is studied from the special education teachers' perspective by analysing their descriptions. The following research question is addressed: How do special education teachers perceive collaboration in the IEP goal-setting process for pupils with the AACM?

\section{Materials and Methods}

\subsection{Participants}

Sixty-five Finnish special education teachers using the AACM participated in the study (female: $92.3 \%$; male: $7.7 \%$; work experience as a special education teacher: mean $=12.7$ years, min. $/$ max. $=4$ months $/ 31.5$ years). The participants taught approximately 15 per cent $(\mathrm{N}=315)$ of all students with the AACM; see [12,49,50]. Two pairs of participants had amalgamated their classes. Participants' classes had one to nine pupils with the AACM $($ mean $=5.0)$ and one to seven special needs assistants (mean $=4.2)$. The participants taught pupils with the AACM from 1st to 10th grade. The majority of the interviewees' pupils lived full time with their parents; 41.5 per cent of the interviewees taught at least one pupil who lived in a group home either full- or part-time. Participants' pupils typically had one or more therapies, e.g., speech therapy or occupational therapy. The therapists were either school staff or from other organisations, and some of the latter also conducted their therapy sessions in school facilities. Most of the participants (87.7\%) had a formal qualification to teach in the AACM classes (MA degree in special education or other). The participants worked in both special schools and in regular schools. Schools were selected by snowball sampling [51] and they were located evenly over Finland. To conclude, the participants represented the target group comprehensively. 


\subsection{Interviews}

Data were collected with semi-structured interviews [52,53] between 2018 and 2020. The method enabled the interviews to be somewhat systematic, but also let the participants express their perspectives comprehensively in a conversational situation with specified questions added to the tentative interview protocol; see [54] (pp. 197-198). The interview guide consisted of 34 questions tailored for seven themes (main elements and structure of teaching, pupils, implementation of the AACM, successes, worries, professional background and the future). The IEPs were discussed especially in the theme "main elements and structure of teaching". The interviews averaged $48.3 \mathrm{~min}$ and consisted of 978.5 pages of interview transcripts. The individual interviews were conducted during participants working hours with one or two interviewers. The interviews were conducted in peaceful environments mainly in the participants' schools. All participants signed a consent form in which their anonymity during the research was granted. The participants were informed that they could withdraw from the study at any time or decline to answer any question. The interviews were recorded and transcribed verbatim.

\subsection{Data Analysis}

The transcribed data were imported into ATLAS.ti (version 8) software, to which a thematic network analysis [55] was applied. The analysis was directed on the participation and collaboration in the IEP goal-setting process, which was examined through the interviewees' views. Each unit of analysis described the input of a professional, family member or other, who somehow participated in the goal-setting process. Descriptions of utilising documents written by professionals who were not a part of the current IEP process were excluded (e.g., documents written by day care or previous special education teacher).

The data were analysed by applying the thematic network analysis [55] based on Toulmin's [56] argumentation theory. The analysis enabled a hermeneutic way to systematise data both robustly and sensitively. The analysis included formulating three levels of themes in web-like illustrative forms (thematic networks), which enabled analysis of the data in multiple layers and presentation of the same-level themes in a non-hierarchical way; see [55]. According to the method [55], the lowest level of themes are basic themes, which each present the data from a narrow perspective; a group of basic themes forms an organising theme, which summarises the principal assumption of the combined basic themes; the superordinate global theme presents the entire data by forming an assertion based on the organising themes.

The analysis entailed six complementary steps: inductive coding, identifying themes, constructing thematic networks, describing and exploring thematic networks, summarising thematic networks and interpreting patterns; see [55]. The inductive coding and identification of themes were done in three parts. In the first part, 30 transcripts were read and coded, and preliminary basic themes were formed. The codes described the participation of different groups in the goal-setting process (e.g., therapists and dialogicality; therapists and instructionality). In the second part, 29 interviews were coded according to the basic themes already formed. Furthermore, organising and global themes were identified. Finally, in part three, six transcripts were coded with the existing themes. Negative cases and disconfirming evidence in parts two and three were coded with new or revised codes; see $[54,57]$. The selected citations in the results were transcribed from Finnish.

\subsection{Ethical Considerations}

The research follows the guidelines of responsible conduct of research by ALLEA [58], IASSID [59] and RCR [60]. Proper permissions to conduct research were acquired from the interviewees, schools and municipalities. The identifiable data were made anonymous in accordance with the EU General Data Protection Regulation [61]. 


\section{Results}

The groups that were mentioned as participating in the AACM goal-setting process with the participants were parents (this group includes other guardians that the pupils may have, but the term 'parents' has been used throughout the text for readability), therapists, special needs assistants, special education teacher colleagues, group home staff, pupils, principals, social workers, and school staff from the morning and afternoon activities. The first three groups (parents, therapists, and special needs assistants) recurred throughout the dataset, and their input was described abundantly. They comprised the first organising theme, main mediators. The other six groups were all mentioned only a few times and their input was usually described sparsely; issues related to them were not particularly prominent in the interview data. They comprised the second organising theme, side mediators. These two organising themes formed the global theme: special education teachers regulate IEP team members' collaboration when setting goals for pupils with the AACM. The thematic network of these results is presented in Figure 1.

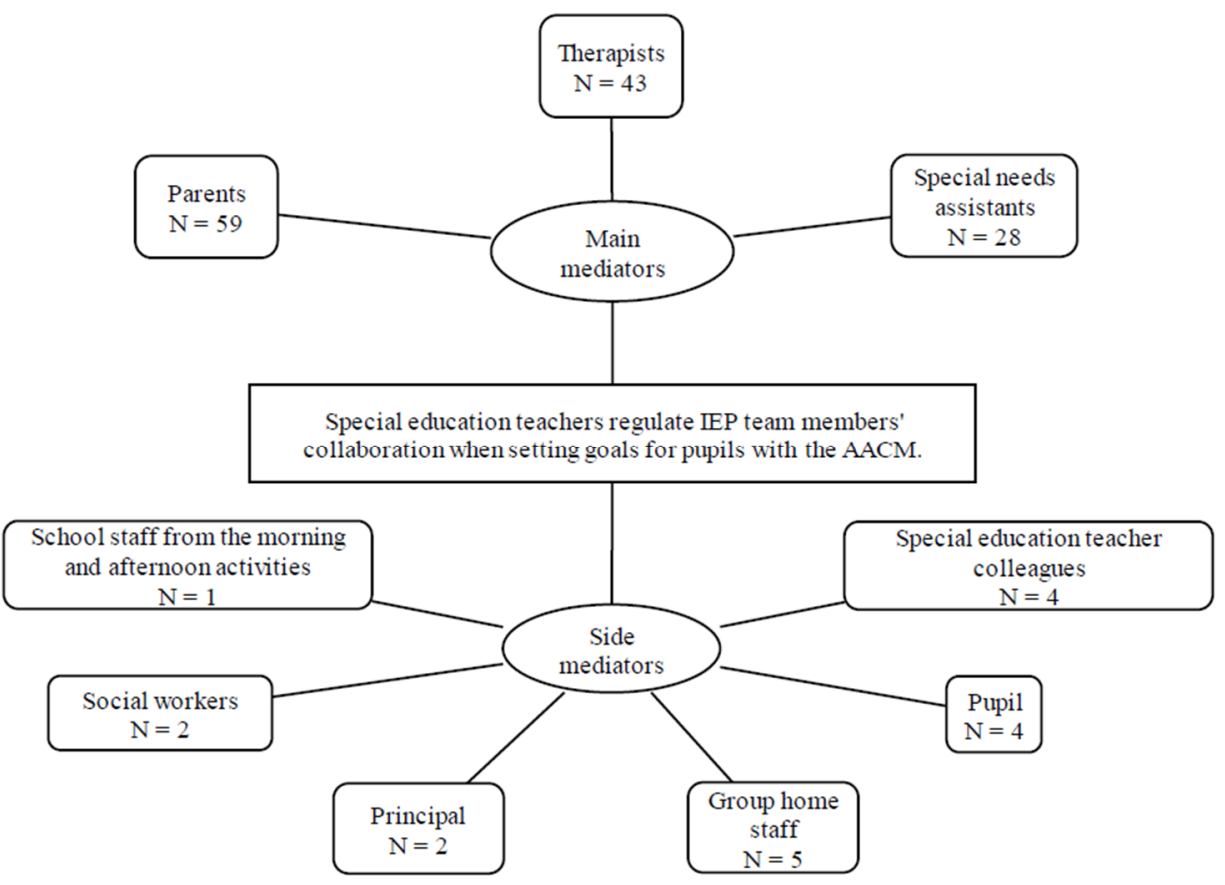

Figure 1. Thematic network for the global theme: "special education teachers regulate Individual Education Plan (IEP) team members' collaboration when setting goals for pupils with the activity area-based curriculum model (AACM)."

The thematic network of a single special education teacher typically consisted of two or three main mediators, parents being one of them. At the widest, the network consisted of all main mediators and two side mediators. The narrowest networks consisted of one mediator, typically parents. However, it should be noted that although not mentioned in the interviews, other mediators might have still participated in the goal-setting process.

\subsection{Main Mediators}

\subsubsection{Parents}

Parents appeared to have the most significant role going through the first parts of the analysis-they were the most frequent and visible group. Several participants described the importance and value of the information mediated by parents. Some participants highlighted how parents knew their child the best, and the information they mediated was necessary, especially in the first grades or with a new pupil. The information that the parents mediated was described as focusing mainly on parents' needs and hopes relating to their child's daily life and future, and participants appeared to value the opportunity to 
facilitate the families' everyday lives (see T14 below). Parents' hopes were integrated into two particular activity areas: activities of daily living and cognitive skills (e.g., reading).

"Well, I discuss a lot with the parents and acknowledge their point of view. For instance, if at home there's something that they struggle with in their everyday life, then together we can try to figure out if there's a way of working on these struggles at school." (T14)

Parents' participation in the goal-setting process as an active mediator was sometimes described as varying. Some parents' hopes were described as being minor or that the parents did not bring them forward. Participant T17 explained this as being due to some pupils' different behaviour at school and at home:

"Well, of course, the parents always show up showing interest. But, aside from one exception, the parents pretty much just listen to what the school and therapists have to say. So only rarely does anyone bring forth their own wishes or anything like that. But often it can be detected that many of our pupils behave slightly differently at school compared to the way they behave at home." (T17)

In concluding about the parents' roles, they were seen as irreplaceable mediators. However, it can be stated that the process contains power, tensions and deviation. Some participants described how they gave parents significant power to influence their child's IEP goals. For example, one participant commented on how they had stopped the pupil's numeracy training and focused more on vocabulary, based on the parents' wish. Having enough time in the IEP meeting and preparation options were central for parents to be able to state their views. Some participants described taking a more powerful role themselves. Participant T60 described how parents' views were heard, but the teacher had the power to decide on the final goals, and there was not enough time to discuss all goals together.

"It's a dialogue, but if we were to go through all the possible goals the conversation would take up a lot of time. [ ... ] But there are a lot of goals that just the teacher sets to the final IEP." (T60)

One participant stated how "in practice, the teacher sets the goals alone", and they are discussed with the parents after. Another interviewee described how some parents gave him too much advice, which forced him to "put the brakes on and negotiate for more realistic goals". Some interviewees were concerned about how much other teachers listen to other IEP team members in the goal-setting process. Interestingly, some participants stated how they did not always aim to set uniform goals with the parents. Participant T59 specified how reading goals were only meant for school.

"I think it's also good that [ ... ] the home stays separate; [ . . ] that home is home. All the same things that need goals at school do not necessarily need goals set at home. Of course, at home they also aim to get rid of the diaper, or whatever it may be. [ ... ] But maybe when it comes to pedagogical issues, like teaching someone to read or something like that, then we keep it here for ourselves." (T59)

\subsubsection{Therapists}

The interviewees valued the specific knowledge that their pupils' therapists had and wanted to collaborate with them in the goal-setting process. Some participants commented on how therapists mediated information about the therapy goals, which formed a suitable basis for the IEP goals. The participants described how it was important to invest in the goals that were acute in the pupil's therapy, and that the collaboration enabled the therapy goals to be brought into the pupil's daily life. This collaboration and mediation were seen as crucial when setting goals for a new pupil. To conclude, mutual goals were seen as supporting pupils' development.

As with the participation of the parents, the therapists' participation also varied; some therapists were described as gladly participating and taking a significant role, and others to be less willing to participate. In addition, as with the parents' participation, the analysis 
showed that the participation of the therapists held power in the IEP process. Even though the therapists' knowledge was appreciated, the teachers were able to regulate how much they wanted to use it. Some participants described how they did not want the therapists to encroach on the school's responsibilities too much and emphasised how IEP goals are primarily school goals (T50; T51).

"But, I think that I as a teacher am responsible for the IEP document and [ ... ] sometimes it might be that [... ] the therapists would be willing to bring goals to the IEP and daily life [ ... ] a little too much, so then you have to slow it down a little bit." (T50)

"Of course, the therapists have their own specific area of expertise, but it's not like the therapist will say what the school's goals are." (T51)

\subsubsection{Special Needs Assistants}

The special needs assistants (SNAs) working in the participants' classes worked almost without exception with all pupils in the class-only four out of the 315 pupils had personal SNAs. The participants had differing practices on how long the same SNA worked with one pupil, ranging from one lesson to several weeks, typically being a couple of days. SNAs were seen as valuable participants in the goal-setting process, and participants described being "very happy if a special needs assistant can participate". Participants described how the SNAs had valuable and diverse information about the pupils' development and daily life at school because they interacted with the pupils amply during school days. SNAs' knowledge was considered to be useful in forming realistic goals. Some participants emphasised the participation of an experienced SNA, and the SNAs' effort was especially important for teachers, who had not been using the AACM for very long. However, participants did not always see the SNAs' participation as necessary. Participant T45 commented on how SNA's participation in a single pupil's meeting was not essential because the pupils did not have personal assistants, and SNAs worked with all pupils in the class. In addition, the SNAs' participation was described as being difficult to arrange because of school structures (T45), which was compensated for with discussions outside the meeting (T7).

"There not being any personal assistants might be one of the reasons. [ ... ] All our SNAs need to pretty much know all our kids and be prepared to work with each one of them during the day, if needed. So, we haven't seen it as practical to name a specific assistant who would attend the IEP meeting. And then we return to the point that the kids are here from morning to evening. So even though I arrange the IEP meeting outside the lessons, it will likely be difficult to get anyone freed from their work, because they should have available normal working hours [to be able to attend to IEP meeting] and if they do, they are assigned as part of the group. So that has also been one of the reasons [SNAs don't attend the IEP meetings]." (T45)

"So [the SNAs] can't attend all of the IEP meetings, but we go through the IEPs. So when I prepare it, the SNAs will read it and make their own observations, because sometimes they might be, and in fact are, with the child for a longer time." (T7)

\subsection{Side Mediators}

The second organising theme side mediators consisted of information mediated by the pupil, special education teacher colleagues, principal, group home staff, social workers and school staff from the morning and afternoon activities. Each of these six groups were mentioned by only a few participants, as can be seen in Figure 1, and their roles were typically on the periphery of the group. However, special education teacher colleagues were sometimes considered as critical in the goal-setting process. One participant, who had several years' experience working as an SNA and was currently working as a substitute, 
described how other AACM teachers had helped her to set IEP goals. Colleagues' support was considered especially important when setting goals for a new pupil that the colleague had previously taught.

The participants described how it was important to set the goals individually in the IEP process. Nevertheless, pupils themselves were rarely mentioned as mediating information directly about their IEP goals (see T46 for an exception).

"Then of course, we discuss this or make a self-assessment. We have a simple practical form. We go through the pupil's thoughts with them. [ ... ] So, for instance in mathematics, addition exercises, should we practise, what do you think, can you work it out, for example $1+3$, and these kinds of calculations. And what is the pupil's view." (T46)

\section{Discussion}

We used thematic network analysis [55] to describe how special education teachers' perceived collaboration in the IEP goal-setting process for pupils with the AACM. The curriculum model is developed mainly for pupils with profound intellectual and multiple disabilities. Existing studies about collaboration in the IEP goal-setting process have concentrated mainly on parent and pupil input to uncover the goal-setting process for pupils with milder disabilities than PIMD. The findings in previous research have consistently demonstrated significant barriers in parents' and pupils' input and participation; see, e.g., [17]. The present study contributes to bridging the gap in the literature by examining the IEP goal-setting process for pupils with the AACM, most of whom have PIMD, and by focusing on how the information mediated by all IEP team members is combined from the special education teachers' perspective.

The current study found that IEP team members for pupils with the AACM have various positions in the goal-setting process. These positions were divided into two organising themes: main and side mediators. The special education teachers appeared to be leading the collaboration and were positioned in the middle of the main and side mediators. The main mediators were described as key collaborators who had important knowledge about the pupil, while side mediators rarely participated in the process. In addition, single mediator positions were not always clear, and the special education teachers were able to use power to strengthen or diminish a group member's collaborative positioning, either consciously or unconsciously. This was shown especially in the participants' comments on parents' and therapists' input. This power indubitably belongs to the special education teachers as they are responsible for the IEP goals' setting and they have the professional ability to formulate them. Nevertheless, some participants appeared to be using more power than others, which highlighted the tensions of the issue-can the special education teacher use power too amply or too sparsely? Next, the perspectives of main and side mediators' collaborative positions are discussed.

\subsection{Main Mediators' Collaborative Positions}

According to the results, parents' participation in the goal-setting process varied. On the one hand, it can be seen as expected, considering individual resources and wishes, and previous studies [23] including pupils receiving varying special education services, some of them having intellectual disabilities. On the other hand, if parents' hopes are described as being noticeably sparse, it raises the question of whether they truly had the opportunity to state their views. (Do parents know what is anticipated of them and have they had sufficient time to familiarise themselves with the IEP? Are the IEP goals presented to the parents as final or as a draft and is there sufficient time to discuss them in the meeting?)

The question regarding parents' lack of participation opportunities seems to be supported by similar previous research. For example, Ruppar and Gaffney [31] found that the IEP team members held opinions that they did not express in the meeting, and Stroggilos and Xanthacou [32] reported how teachers and other professionals wanted to include the parents in the goal-setting process but failed to give the parents the opportunity in practice. 
In addition, Kurth and colleagues [27], who studied parents' input and power structures through 88 IEPs prepared for pupils with intellectual and developmental disabilities, revealed that parents' hopes and concerns recorded in the IEPs were formulated into goals or services only two-thirds of the time; see also [36]. The power structures could also be seen in their analysis of the wording of the IEPs, which implied that the IEP teams were composed of school personnel who gathered information about the families ("the IEP team has requested and considered the concerns of Parents(s)/Educational decision maker") [27] (p. 494). The current study adds to the previous research that, similar to parents of pupils without the AACM or PIMD, the participation of parents of pupils with the AACM or PIMD varies in the goal-setting process. This might be highly connected to parents' recourses, considering the countless meetings and documents that they have to attend and fill on their child's behalf. Alternatively, it may show the remarkable trust that parents have for the school and teachers and their professional skills. In addition, the results may highlight the trust that various special education teachers had concerning parents' expertise regarding their child. To conclude, the research supports previous findings of the challenges and varieties on parents' participation levels and ways.

When considering the goal setting-process for pupils with milder disabilities than PIMD, there is a central difference in the role of the therapists. Pupils with PIMD might have started various therapies in their early childhood and therapists might have known them longer than school staff. Pupils with milder disabilities, on the other hand, might attend speech therapy for a year or so (for example), or at least have typically fewer therapies than pupils with the AACM or PIMD. The current study therefore adds information of the relationship and goal-setting collaboration of school and therapists, which research related to pupils with milder disabilities than PIMD cannot. Therapists were primarily considered to be crucial main mediators, and participants described how mutual goals of the school and therapists were important. This result was somewhat contradictory with Stroggilos and Xanthacou [32], who discovered that in the United Kingdom, teachers and other professionals, e.g., physiotherapists, had sometimes never discussed the IEP goals together. The result thus shows that the therapists' roles in the goal-setting process for pupils with PIMD may vary between countries. In addition, the dataset in the present study showed that the participants were able to use power when collaborating with the therapists; they were able to regulate (intentionally or unintentionally) how much they would use the therapists' input. This regulation is also essential because the special education teachers are responsible for the IEP goals' setting, they are implementing the Finnish national core curriculum for basic education [2], and the goals are set for school days. However, in addition to parents' varying participation levels, the research shows that teachers' use of power and therapists' participation levels also seem to vary, which highlights the possible difficulties in fulfilling educational equality.

As other main mediators, SNAs were considered to be important collaborators who had unique information about the pupils. The results of this study indicated that AACM teachers had mainly warm and positive relations with the SNAs and the collaboration with them was successful. The role and the job descriptions of SNAs working with pupils with the AACM are very different from the role of SNAs working with pupils with milder disabilities. Basic care, activities of daily living, and motor skills play a central part in the work of the former, while the latter are more focused on cognitive and social skills. In addition, the former typically work with fewer pupils than the latter. Thus, SNAs working with pupils with the AACM have more time to get to know each pupil and, therefore, have more information to share in the IEP process. However, structural contradictions in some circumstances excluded the SNAs from participating in the goal-setting process. This was compensated for with meetings before and after the actual IEP meeting, at which the special education teachers gathered information from the SNAs. These discussions enabled the SNAs to mediate important knowledge about the pupil. That being said, based on previous research, discussions of only part of the IEP team before the actual meeting can raise power imbalances in the process between school and family $[17,28,33]$. The current 
research highlights that SNAs can be active participants in pedagogical decision-making and they might have information that other IEP team members do not, so it is important to enable their participation.

The results highlight that the collaboration in the goal-setting process for pupils with the AACM occurs mainly between the special education teacher, parents, therapists and SNAs. There, the teacher plays a key role. Yet, therapists and SNAs have a particular role in the life of pupils with the AACM or PIMD, and can therefore make significant contributions to the IEP process. Main mediators' active participation in the goal-setting process cannot be taken for granted, but needs to be intentionally promoted.

\subsection{Collaboration of Some Side Mediators}

As with the present results, previous studies have demonstrated that pupils' participation in the IEP goal-setting process has typically been sparse, especially when considering pupils with severe disabilities [23]. However, without exception, the participants in this study described the goal-setting process to be individual for each of their pupils. This leads to the conclusion that information about pupils' interests, and subjects that are meaningful for them, were collected during pupils' everyday lives at school by teachers and SNAs, and from parents as proxy respondents. Thus, pupils' participation in the IEP goal-setting process appeared to be mainly brokered. According to the systematic review and metaanalysis of Sanderson and Goldman [34], interventions involving pupils with PIMD in the goal-setting process are sparse. However, Pearlman and Michaels [62] found that with support and suitable Augmentative and Alternative Communication (AAC) tools, pupils with profound disabilities were able to elicit their views of their lives, and thus, provided valuable information to their educational plans. The current research shows that interventions such as Pearlman and Michaels' [62] are needed for pupils with the AACM in order to strengthen their participation in the IEP goal-setting process, as has been carried out with pupils with milder disabilities [30,63].

Special education teacher colleagues were described as rarely participating in the IEP goal-setting process, and general consultation was not described to be a central part of the IEP goal-setting process. This supports Kokko and colleagues' [64] similar findings in their nationwide survey, where they discovered that from various elements, the views of other teachers influenced teachers teaching pupils with PIMD the least. However, the survey also showed that over 65 per cent of these teachers received some support from other special education teachers in their work [64]. The results of the current research add that the obtained support seems to be focused mainly on other elements than specific IEP goals, and pupil knowledge is considered critical for a colleague to participate in the goal-setting process. However, some participants pointed out the crucial role of the special education teacher colleagues and how they were needed in the goal-setting process. Göransson and colleagues [65] found that teachers working with pupils with intellectual disabilities desired collaboration with each other, and colleagues' support was highly needed. The current research emphasises that the need can also be seen when working with pupils with the AACM and PIMD and when setting their IEP goals.

The difference between the amount of input described in this study for parents and group home staff was considerable, which was somewhat surprising. This result may be explained by the fact that most of the participants' pupils lived with their parents, and participation by group home staff was not relevant. However, almost half of the interviewees taught pupils who lived in a group home either full- or part-time, and none of them described the staff's input abundantly. In addition to confidentiality issues that might challenge the IEP collaboration, this result might reflect on how group homes are seen as separate organisations, with whom schools do not usually collaborate. The difference also highlights how the group home staff might not be viewed as professionals with important knowledge of the pupil. In addition, schools and teachers might have had negative experiences collaborating with group homes in the past. There are various reasons for the difference between the results of the input by parents and group home 
staff. However, it shows that the group home staff might not receive the same type of respect from schools as parents do regarding pupil knowledge. When considering pupils other than those with the AACM or PIMD, group home staff can have a central role in the lives of pupils in foster care. Previous research has highlighted the need for support and development of the collaboration between school and foster care [66], which supports the findings of the current study.

The results of the current study clearly implied that principals were side mediators in the goal-setting process who participated in it rarely. However, previous Finnish research implies that the principals would participate in the IEP process as active participants [64]. This difference might originate due to the specific curriculum model that was the focus of the research; the AACM can be seen as very different from other support models in the Finnish national core curriculum. In addition, the AACM is also provided to a smaller group. Thus, not all principals might be as familiar with the AACM than with other more common support models. Thus, the principals might not have enough professional knowledge to participate in the IEP goal-setting process for pupils with the AACM. In addition, in Kokko and colleagues' [64] research, the participation of the principals was seen as a policy, but the current research inspected how the mediators' roles are actualised in the process from the special education teachers' view. To conclude, the roles of the principals might vary highly between the IEP process of pupils with the AACM or PIMD and pupils with milder disabilities, and the policies do not always actualise.

\subsection{Limitations}

The current research had some limitations that should be acknowledged. Firstly, the study focused on pupils with the AACM, most of them having PIMD, in a specific sociocultural context. Accordingly, one needs to be careful in generalising the results across country contexts. Further studies are needed in other sociocultural contexts to confirm the findings.

Another limitation of the study was that the data were drawn only from special education teachers' interviews, not from questionnaires or from other IEP team members' interviews. Thus, it is important to acknowledge that although not mentioned by a participant, other mediators might still have participated in the goal-setting process. For that reason, the numbers of the main and side mediators were not observed from a quantitative point of view and more attention was given to the descriptions of the quality of their positions. If the data had consisted of answers to a questionnaire, these descriptions would have been significantly narrower. As for the fact that only special education teachers were interviewed, it is not surprising that they were positioned in the middle of other mediators. However, even though the IEPs are formulated in a collaborative process with various mediators, it is not intended that the pupil's teacher, obligated to form and implement the plan, should outsource themselves from the process. Thus, apart from the pupil's teacher and perhaps the pupil themselves, no one else could be in the centre.

\section{Conclusions}

This study has identified power as a recurrent and varying theme in the dataset. Power in favour of the school is necessary, but teachers also need to be aware of it to know when and how to use it. Despite deviations in the IEP teams' power structures, parents were mainly described as active and irreplaceable participants, which was consistent with previous research regarding pupils with PIMD [32,64]. Further research should be undertaken to investigate the implementation of this result; how it could be further strengthened with different models and practices; and how parents' input shows in the IEP goals prepared for pupils with the AACM or PIMD. In addition, multi-professional practices and methods should be researched and developed to reinforce the positions of group home staff, special education teacher colleagues and the pupils with the AACM or PIMD. Previous research has introduced different models and practices that can be used to balance the power structures of the participants' roles in educational decision-making, and 
could thus be used in the IEP process for pupils with the AACM or PIMD. These include a shared leadership model $[33,67]$ and building teams with interprofessional collaborative practice [47].

Pupils with the AACM and PIMD have often been left outside the inclusion debate and practices. Their teachers do not necessarily collaborate with colleagues to the same extent as teachers who use inclusion and integration daily to guide their actions. Collaboration has been distinguished as a key element in improving inclusive practises [68], and the opportunities for teachers' reciprocal collaboration in the IEP goal-setting process for pupils with the AACM or PIMD thus need further research. Collaboration between (special education) teachers in the process enables the sharing of good practices and contributes to the possibilities of inclusive practices.

We state that successful collaboration in the IEP goal-setting process promotes the setting of appropriate and comprehensive goals; see [39]. As for the appropriate and comprehensive goals, these promote pupils' learning processes and outcomes $[69,70]$. To develop a full picture of the options for collaboration in the IEP goal-setting process for pupils with the AACM or PIMD, additional studies will be needed to investigate the opportunities and means to include pupils as active main mediators.

Author Contributions: Conceptualization, S.P., R.P., K.P. and E.K.K.; Data curation, S.P. and R.P.; Formal analysis, S.P.; Funding acquisition, E.K.K.; Investigation, S.P., R.P. and E.K.K.; Methodology, S.P.; Project administration, S.P.; Supervision, E.K.K.; Validation, S.P., R.P. and E.K.K.; Visualization, S.P.; Writing—original draft, S.P.; Writing—review \& editing, S.P., R.P., K.P. and E.K.K. All authors have read and agreed to the published version of the manuscript.

Funding: The APC was funded by the Helsinki University Library.

Institutional Review Board Statement: In Finland, The Finnish National Board on Research Integrity [71] has stated, that an ethical review statement is required when the research deviates from the principle of informed consent; intervenes in the physical integrity of research participants; involves participants under the age of 15 being studied without parental consent; exposes participants to exceptionally strong stimuli; risks to cause mental harm that exceeds the limits of normal daily life; or involves a safety threat. Thus, Ethical review and approval were waived for this study, due to the reason that the study did not fulfil the conditions stated by the Finnish National Board on Research Integrity.

Informed Consent Statement: Informed consent was obtained from all subjects involved in the study.

Data Availability Statement: Certain sections of data are available on request from the corresponding author but are not publicly available to ensure the privacy of the participants.

Acknowledgments: The data were collected as part of the INTO research project.

Conflicts of Interest: The authors declare no conflict of interest.

\section{References}

1. Eckhoff, D.O.; Weiss, J. Goal setting: A concept analysis. Nurs. Forum 2020, 55, 275-281. [CrossRef]

2. Finnish National Agency for Education. The National Core Curriculum for Basic Education 2014, 4th ed.; Finnish National Agency for Education: Helsinki, Finland, 2014.

3. Parliament of Finland. BEA 628/1998. Perusopetuslaki. The Basic Education Act 628/1998. Available online: https://www.finlex. fi/fi/laki/ajantasa/1998/19980628 (accessed on 1 June 2021).

4. Andreasson, I.; Asp-Onsjö, L.; Isaksson, J. Lessons learned from research on individual educational plans in Sweden: Obstacles, opportunities and future challenges. Eur. J. Spec. Needs Educ. 2013, 28, 413-426. [CrossRef]

5. The U.S. Department of Education. Individuals with Disabilities Education Act (IDEA). 2004. Available online: https:/ / sites.ed. gov/idea/about-idea/ (accessed on 3 September 2021).

6. Parliament of Finland. BEA Amendment 642/2010. Laki Perusopetuslain Muuttamisesta. The Basic Education Act Amendment 642/2010. Available online: https:/ /www.finlex.fi/fi/laki/alkup/2010/20100642 (accessed on 1 June 2021).

7. Parliament of Finland. Pupil and Student Welfare Act 1287/2013. Available online: https://www.finlex.fi/fi/laki/alkup/2013/2 0131287 (accessed on 1 June 2021). 
8. Sahin, H. The development of individualized educational programs in Turkey IEP applications. Procedia-Soc. Behav. Sci. 2012, 46, 5030-5034. [CrossRef]

9. Sanches-Ferreira, M.; Lopes-dos-Santos, P.; Alves, S.; Santos, M.; Silveira-Maia, M. How individualised are the Individualised Education Programmes (IEPs): An analysis of the contents and quality of the IEPs goals. Eur. J. Spec. Needs Educ. 2013, 28, 507-520. [CrossRef]

10. Kontu, E.K.; Pirttimaa, R.A. Teaching methods and curriculum models used in Finland in the education of students diagnosed with having severe/profound intellectual disabilities. Br. J. Learn. Disabil. 2009, 38, 175-179. [CrossRef]

11. The Ministry of Education and Culture. Valtioneuvoston Asetus Perusopetuslaissa Tarkoitetun Opetuksen Valtakunnallisista Tavoitteista ja Perusopetuksen Tuntijaosta. Government Decree on the National Objectives for Education Referred to in the Basic Education Act and on the Distribution of Lesson Hours (422/2012). Available online: https://www.finlex.fi/fi/laki/alkup/2012 /20120422 (accessed on 1 June 2021).

12. Official Statistics of Finland (OSF): Special Education. ISSN=1799-1617. 2019, Appendix Table 6. Pupils Having Received Special Support on Grades 1-9 and During Additional Education of Comprehensive School by Subject Syllabus. 2019. Available online: http://www.stat.fi/til/erop/2019/erop_2019_2020-06-05_tau_006_en.html (accessed on 15 June 2021).

13. Rakap, S. Quality of individualised education programme goals and objectives for preschool children with disabilities. Eur. J. Spec. Needs Educ. 2015, 30, 173-186. [CrossRef]

14. Rowland, C.M.; Quinn, E.D.; Steiner, S.A.M. Beyond legal: Crafting high-quality IEPs for children with complex communication needs. Commun. Disord. Q. 2015, 37, 53-62. [CrossRef]

15. Ruble, L.; McGrew, J.H. Teacher and child predictors of achieving IEP goals of children with autism. J. Autism Dev. Disord. 2013, 43, 2748-2763. [CrossRef] [PubMed]

16. Farquharson, K.; Tambyraja, S.R.; Justice, L.M.; Redle, E.E. IEP goals for school-age children with speech sound disorders. J. Commun. Disord. 2014, 52, 184-195. [CrossRef] [PubMed]

17. Blackwell, W.H.; Rossetti, Z.S. The development of Individualized Education Programs: Where have we been and where should we go now? SAGE Open 2014, 4, 1-15. [CrossRef]

18. Boavida, T.; Aguiar, C.; McWilliam, R.A.; Pimentel, J.S. Quality of individualized education program goals of preschoolers with disabilities. Infants Young Child. 2010, 23, 233-243. [CrossRef]

19. Ruble, L.A.; McGrew, J.; Dalrymple, N.; Jung, L.A. Examining the quality of IEPs for young children with autism. J. Autism Dev. Disord. 2010, 40, 1459-1470. [CrossRef] [PubMed]

20. Räty, L.; Vehkakoski, T.; Pirttimaa, R. Documenting pedagogical support measures in Finnish IEPs for students with intellectual disability. Eur. J. Spec. Needs Educ. 2019, 34, 35-49. [CrossRef]

21. Kartika, A.; Suminar, D.R.; Tairas, M.M.W.; Hendriani, W. Individual Education Program (IEP) paperwork: A narrative review. Int. J. Eng. Technol. 2018, 7, 682-687. [CrossRef]

22. Barnard-Brak, L.; Lechtenberger, D. Student IEP participation and academic achievement across time. Remedial Spec. Educ. 2010, 31, 343-349. [CrossRef]

23. Wagner, M.; Newman, L.; Cameto, R. A national picture of parent and youth participation in IEP and transition planning meetings. J. Disabil. Policy Stud. 2012, 23, 140-155. [CrossRef]

24. Williams-Diehm, K.L.; Brandes, J.A.; Chesnut, P.W.; Haring, K.A. Student and parent IEP collaboration: A comparison across school settings. Rural. Spec. Educ. Q. 2014, 33, 3-11. [CrossRef]

25. MacLeod, K.; Causton, J.N.; Radel, M.; Radel, P. Rethinking the Individualized Education Plan process: Voices from the other side of the table. Disabil. Soc. 2017, 32, 381-400. [CrossRef]

26. Zagona, A.L.; Miller, A.L.; Kurth, J.A.; Love, H. Parent perspectives on special education services: How do schools implement team decisions? Sch. Community J. 2019, 29, 105-128.

27. Kurth, J.A.; McQueston, J.A.; Ruppar, A.L.; Toews, S.G.; Johnston, R.; McCabe, K.M. A description of parent input in IEP development through analysis IEP documents. Intellect. Dev. Disabil. 2019, 57, 485-498. [CrossRef]

28. Nelson, C. Family and School Activation of Cultural Capital in the Individualized Education Plan (IEP) Process. Ph.D. Thesis, Northern Illinois University, DeKalb, IL, USA, 2015.

29. (Van Dycke) Doronkin, J.L.; Martin, J.E.; Greene, B.A.; Choiseul-Praslin, B. Opening Oz's curtain: Who's really running the annual IEP meeting to discuss secondary transition issues? J. Res. Spec. Educ. Needs 2020, 20, 206-216. [CrossRef]

30. Martin, J.E.; Van Dycke, J.L.; Christensen, W.R.; Greene, B.A.; Gardner, J.E.; Lovett, D.L. Increasing student participation in IEP meetings: Establishing the self-directed IEP as an evidenced-based practice. Except. Child. 2006, 72, 299-316. [CrossRef]

31. Ruppar, A.L.; Gaffney, J.S. Individualized Education Program team decisions: A preliminary study of conversations, negotiations, and power. Res. Pract. Pers. Sev. Disabil. 2011, 36, 11-22. [CrossRef]

32. Stroggilos, V.; Xanthacou, Y. Collaborative IEPs for the education of pupils with profound and multiple learning difficulties. Eur. J. Spec. Needs Educ. 2006, 21, 339-349. [CrossRef]

33. Love, H.R.; Zagona, A.L.; Kurth, J.A.; Miller, A.L. Parents' experiences in educational decision making for children and youth with disabilities. Inclusion 2017, 5, 158-172. [CrossRef]

34. Sanderson, K.A.; Goldman, S.E. A systematic review and meta-analysis of interventions used to increase adolescent IEP meeting participation. Career Dev. Transit. Except. Individ. 2020, 43, 157-168. [CrossRef] 
35. Bergin, E.; Logan, A. An individual education plan for pupils with special educational needs: How inclusive is the process for the pupil? REACH J. Incl. Educ. Irel. 2013, 26, 79-91.

36. Heiskanen, N.; Alasuutari, M.; Vehkakoski, T. Intertextual voices of children, parents, and specialists in Individual Education Plans. Scand. J. Educ. Res. 2019, 65, 36-53. [CrossRef]

37. Martin, J.E.; Van Dycke, J.L.; Greene, B.A.; Gardner, J.E.; Christensen, W.R.; Woods, L.L.; Lovett, D.L. Direct observation of teacher-directed IEP meetings: Establishing the need for student IEP meeting instruction. Except. Child. 2006, 72, 187-200. [CrossRef]

38. Paccaud, A.; Luder, R. Participation versus individual support: Individual goals and curricular access in inclusive special needs education. J. Cogn. Educ. Psychol. 2017, 16, 205-224. [CrossRef]

39. King, F.; Bhroin, O.N.; Prunty, A. Professional learning and the individual education plan process: Implications for teacher educators. Prof. Dev. Educ. 2018, 44, 607-621. [CrossRef]

40. Christle, C.A.; Yell, M.L. Individualized Education Programs: Legal requirements and research findings. Exceptionality 2010, 18, 109-123. [CrossRef]

41. Nakken, H.; Vlaskamp, C. A need for a taxonomy for profound intellectual and multiple disabilities. J. Policy Pract. Intellect. Disabil. 2007, 4, 83-87. [CrossRef]

42. Luckasson, R.; Borthwick-Duffy, S.; Buntinx, W.H.E.; Coulter, D.L.; Craig, E.M.P.; Reeve, A.; Schalock, R.L.; Snell, M.E.; Spitalnik, D.M.; Spreat, S.; et al. Mental Retardation: Definition, Classification, and Systems of Supports, 10th ed.; American Association on Mental Retardation: Washington, DC, USA, 2002.

43. Launonen, K. Vuorovaikutus: Kehitys, Riskit ja Tukeminen Kuntoutuksen Keinoin; Kehitysvammaliitto ry, Oppimateriaalikeskus Opike: Helsinki, Finland, 2007.

44. Timothy, S.; Agbenyega, J.S. Insider perspectives on catalysing the development and use of individualised education plans. Int. J. Incl. Educ. 2019, 1-15. [CrossRef]

45. Etscheidt, S.; Knesting, K. A qualitative analysis of factors influencing the interpersonal dynamics of a prereferral team. Sch. Psychol. Q. 2007, 22, 264-288. [CrossRef]

46. Martin, J.E.; Marshall, L.H.; Sale, P. A 3-year study of middle, junior high, and high school IEP meetings. Except. Child. 2004, 70, 285-297. [CrossRef]

47. Cooper-Duffy, K.; Eaker, K. Effective team practices: Interprofessional contributions to communication issues with a parent's perspective. Am. J. Speech-Lang. Pathol. 2017, 26, 181-192. [CrossRef]

48. Clarke, D.; Hollingsworth, H. Elaborating a model of teacher professional growth. Teach. Teach. Educ. 2002, 18, 947-967. [CrossRef]

49. Kontu, E.; Pirttimaa, R. The assessment of severely intellectually disabled students. Eur. J. Spec. Needs Educ. 2008, 23, 75-80. [CrossRef]

50. Jahnukainen, M.; Korhonen, A. Integration of students with severe and profound intellectual disabilities into the comprehensive school system: Teachers' perceptions of the education reform in Finland. Int. J. Disabil. Dev. Educ. 2003, 50, 169-180. [CrossRef]

51. Sadler, G.R.; Lee, H.-C.; Lim, R.S.-H.; Fullerton, J. Recruitment of hard-to-reach population subgroups via adaptations of the snowball sampling strategy. Nurs. Health Sci. 2010, 12, 369-374. [CrossRef] [PubMed]

52. Lune, H.; Berg, B.L. Qualitative Research Methods for the Social Sciences; Pearson: Harlow, UK, 2017.

53. Patton, M.Q. Qualitative Research E Evaluation Methods: Integrating Theory and Practice, 4th ed.; SAGE Publications: Thousand Oaks, CA, USA, 2014.

54. Brantlinger, E.; Jimenez, R.; Klingner, J.; Pugach, M.; Richardson, V. Qualitative studies in special education. Except. Child. 2005, 71, 195-207. [CrossRef]

55. Attride-Stirling, J. Thematic networks: An analytic tool for qualitative research. Qual. Res. 2001, 1, 385-405. [CrossRef]

56. Toulmin, S.E. The Uses of Argument; Cambridge University Press: Cambridge, UK, 1958.

57. Patton, M.Q. Enhancing the quality and credibility of qualitative analysis. Health Serv. Res. 1999, 34, 1189-1208.

58. ALLEA-All European Academies. The European Code of Conduct for Research Integrity; ALLEA-All European Academies: Berlin, Germany, 2017.

59. Dalton, A.J.; McVilly, K.R. Ethics guidelines for international, multicenter research involving people with intellectual disabilities. J. Policy Pract. Intellect. Disabil. 2004, 1, 57-70. [CrossRef]

60. Finnish Advisory Board on Research Integrity. Responsible Conduct of Research and Procedures for Handling Allegations of Misconduct in Finland: Guidelines of the Finnish Advisory Board on Research Integrity 2012; Finnish Advisory Board on Research Integrity: Helsinki, Finland, 2013.

61. EU General Data Protection Regulation. 2016. Available online: http://www.privacy-regulation.eu/fi/r26.htm (accessed on 1 October 2020).

62. Pearlman, S.; Michaels, D. Hearing the voice of children and young people with a learning disability during the Educational Health Care Plan (EHCP). Support Learn. 2019, 34, 148-161. [CrossRef]

63. Mitchell, D.; Morton, M.; Hornby, G. Review of the Literature on Individual Education Plans; Ministry of Education: Wellington, New Zealand, 2010.

64. Kokko, T.P.; Pesonen, H.; Polet, J.; Kontu, E.; Ojala, T.; Pirttimaa, R. Erityinen tuki Perusopetuksen Oppilaille, Joilla tuen Tarpeen Taustalla on Vakavia Psyykkisiä Ongelmia, Kehitysvamma-Tai Autismin Kirjon Diagnoosi: VETURI-Hankkeen Kartoitus; Helsingin Yliopisto: Helsinki, Finland; Jyväskylän Yliopisto: Jyväskylä, Finland, 2013. 
65. Göransson, K.; Bengtsson, K.; Hansson, S.; Klang, N.; Lindqvist, G.; Nilholm, C. Segregated education as a challenge to inclusive processes: A total population study of Swedish teachers' views on education for pupils with intellectual disability. Int. J. Incl. Educ. 2020, 1-16. [CrossRef]

66. Pirttimaa, R.; Välivaara, C. Educational intervention planning for children in foster care in Finland: A case study. Educ. Inq. 2018, 9, 237-246. [CrossRef]

67. Gordon, M.F.; Louis, K.S. Linking parent and community involvement with student achievement: Comparing principal and teacher perceptions of stakeholder influence. Am. J. Educ. 2009, 116, 1-31. [CrossRef]

68. Paju, B. An Expanded Conceptual and Pedagogical Model of Inclusive Collaborative Teaching Activities. Ph.D. Thesis, University of Helsinki, Helsinki, Finland, 2021.

69. Locke, E.A.; Latham, G.P. Building a practically useful theory of goal setting and task motivation. A 35-year odyssey. Am. Psychol. 2002, 57, 705-717. [CrossRef]

70. Locke, E.A.; Latham, G.P. New directions in goal-setting theory. Curr. Dir. Psychol. Sci. 2006, 15, 265-268. [CrossRef]

71. Finnish National Board on Research Integrity. The Ethical Principles of Research with Human Participants and Ethical Review in the Human Sciences in Finland, 2nd ed.; Finnish National Board on Research Integrity: Helsinki, Finland, 2019. 